\title{
Schmitt Trigger Circuits using Various Active Devices
}

\author{
K. Vijaya Vardhan, K. Malathi Santhoshini, Sarada Musala, V N Lakshmi Pabbisetty,
}

\begin{abstract}
A$ vast number of diverse analog circuit blocks have been arosed in the past few decades. A various active devices are Operational Amplifier (Op-Amp), Current Conveyor (CC), Operational Transconductance Amplifier (OTA), Differential Difference Current Conveyor (DDCC), Differential Difference Current Conveyor Transconductnace Amplifier (DDCCTA), Z-Copy Current Differencing Transconductance Amplifier (ZC-CDTA), Voltage Difference Transconductance Amplifier (VDTA) and so on. A review on Schmitt trigger circuits by using different active devices are presented in this paper since Schmitt trigger circuits are widely used in numerous applications such as in waveform generators, wave-shaping circuits, comparators, Bio-medical applications, analog processing systems, communication and instrumentation systems.
\end{abstract}

Keywords- Schmitt Trigger; Op-Amp; CC; OTA; DDCC; ZC-CDTA; DDCCTA; VDTA.

\section{INTRODUCTION}

As technology is improving day-by-day, the demand has increased on fabrication of analogue and digital circuits on a chip. This creates an attention for the designers to do research in these domains. Some of the analogue and digital circuits are devised availing MOSFETs rather than BJTs since they have small size, less noise and low power dissipation. One such circuit amid those is the Schmitt trigger. A Schmitt trigger circuit has the property of converting any analog signal into a digital signal, i.e., a square signal. In 1938, Otto H Schmitt [1] developed a Schmitt trigger namely, the Thermionic Trigger. By using various active devices, the Schmitt trigger circuits are designed. Those are, Operational Amplifier (Op-Amp), Current Conveyor (CC), Operational Transconductance Amplifier (OTA), Differential Difference Current Conveyor (DDCC), Differential Difference Current Conveyor Transconductnace Amplifier (DDCCTA), Z- Copy Current Differencing Transconductance Amplifier (ZCCDTA), Voltage Difference Transconductance Amplifier (VDTA) and so on. This paper presents a literature review on the designed Schmitt triggers [1-14] and their applications in different wave-shaping circuits, comparators, waveform generators, analog processing systems, Bio-medical systems and communication systems.

Revised Manuscript Received on December 15, 2019.

K. Vijaya Vardhan, Dept. of Electronics \& Communication Engineering Vignan's LARA Institute of Technology \& Science. kvvardhan405@gmail.com

K. Malathi Santhoshini, Dept. of Electronics \& Communication Engineering Vignan's LARA Institute of Technology \& Science. malathi06.kaza@gmail.com

Sarada Musala, Dept. of Electronics \& Communication Engineering Vignan's Foundation for Science, Technology \& Research, Deemed to be Univeristy, Vadlamudi, A.P, India sarada.marasu@gmail.com

V N Lakshmi Pabbisetty, Dept. of Electronics \& Communication Engineering Vignan's LARA Institute of Technology \& Science. mahalakster@gmail.com

\section{REVIEW OF EXISTING SCHMITT TRIGGERS}

By depending upon the avail of technology and the power consumption of circuit with the use of supply voltage, various number of Schmitt triggers are designed with different active devices.

\section{A. Schmitt Trigger using Operational Amplifier (Op-Amp)}

A Schmitt trigger is designed using Operational Amplifier with the use of resistors [2] and is shown in Figure 1. The output voltage can be mathematically expressed as,

$$
V_{o}= \pm V_{\text {sat }}
$$

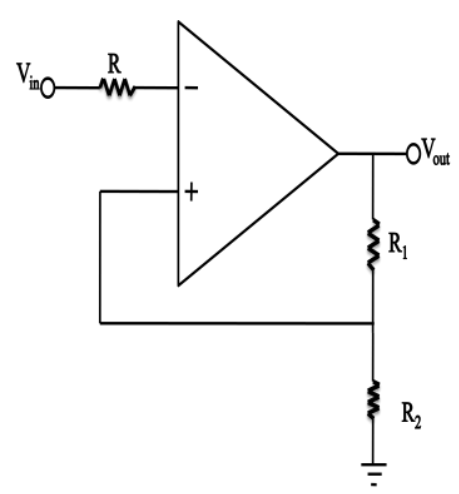

Figure. 1 Schmitt trigger uses Op-Amp

The triggering points can be varied by varying the resistor values which provides an advantage where as the disadvantage is, it avails three passive elements to obtain Schmitt trigger operation and uses high supply voltage.

B. Schmitt Trigger using Operational Transconductance Amplifier (OTA)

Figure 2 presents a Schmitt trigger circuit [3] availing two OTA's. These two OTA's are connected in positive feedback loop. The output voltage of Schmitt trigger can be expressed as,

$$
V_{O}=\left\{\begin{array}{rll}
I_{B 1} R_{1} & \text { when } & V_{\text {in }} \geq 0 \\
-I_{B 1} R_{1} & \text { when } & V_{\text {in }} \leq 0
\end{array}\right\}
$$




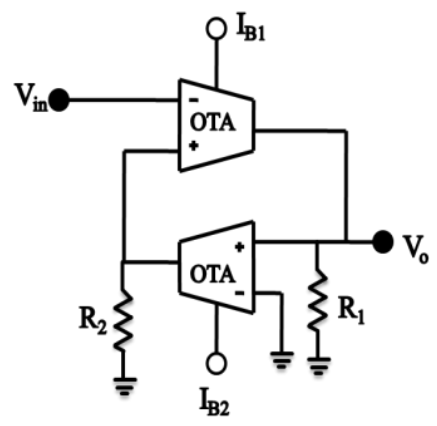

Figure. 2 Current controllable OTA-R Schmitt trigger

The upper triggering point $\left(\mathrm{V}_{\mathrm{TH}}\right)$ and the lower triggering point $\left(\mathrm{V}_{\mathrm{TL}}\right)$ is given as,

$$
\begin{aligned}
& V_{T H}=I_{B 2} R_{2} \\
& V_{T L}=I_{B 1} R_{1}
\end{aligned}
$$

The advantage of this circuit is hysteresis curve can be adjustable with the help of bias currents. The disadvantage of the circuit is usage of two active blocks, two resistors and avails $\pm 10 \mathrm{~V}$ supply voltage.

\section{Schmitt trigger uses Current Conveyors (CC)}

A Schmitt trigger circuit [4] is implemented with the use of Second generation Current Conveyor (CCII+). The circuit is shown in Figure 3.

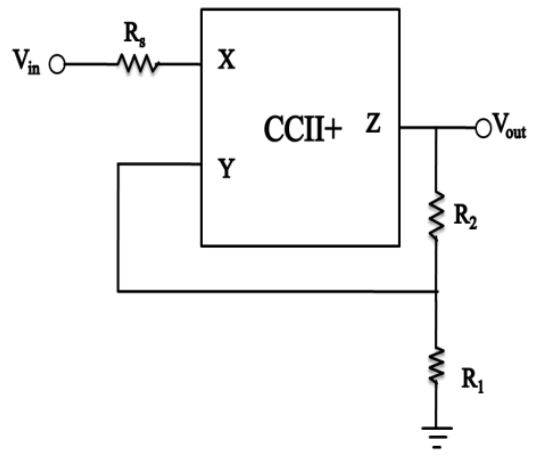

Figure. 3 CCII+ based Schmitt trigger

The output state of this circuit will have two stable states which is $\mathrm{V}_{\text {satH }}$, and $\mathrm{V}_{\text {satL. The upper triggering }}$ point and the lower triggering point are given as,

$$
\begin{aligned}
& V_{T H}=\frac{R_{1}-R_{s}}{R_{1}+R_{2}} V_{\text {sat } H} \\
& V_{T L}=-\frac{R_{1}-R_{s}}{R_{1}+R_{2}} V_{\text {sat } L}
\end{aligned}
$$

The advantage of this circuit is hysteresis curve can be adjustable with the help of bias currents. The disadvantage of the circuit is usage of three resistors and avails $\pm 5 \mathrm{~V}$ supply voltage.

\section{Schmitt trigger uses Differential Difference Current Conveyor (DDCC)}

With the use of active device namely, Differential Difference Current Conveyor (DDCC) a Schmitt trigger circuit [10] is constructed by availing single DDCC with use of two resistors and is shown in Figure 4. The saturated output voltage is equal to $\pm \mathrm{V}_{\text {sat }}$. The upper threshold voltage and lower threshold voltage is given as,

$$
V_{T H}=\frac{+V_{s a t} R_{1}}{R_{1}+R_{2}}
$$

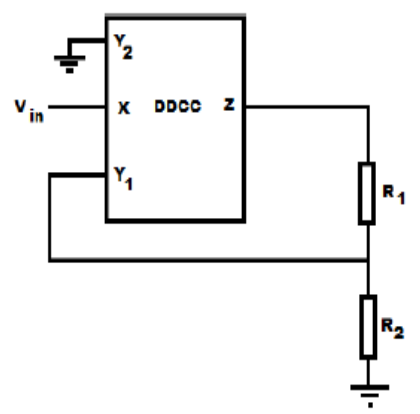

Figure. 4 Schmitt trigger using DDCC

The circuit is examined using PSPICE Level-3 parameters in $0.5 \mu \mathrm{m}$ MIETEC process. It uses a supply voltage of $\pm 2.5 \mathrm{~V}$. The main drawback of this circuit is the threshold voltage depends on the use of resistor values

\section{E. Schmitt trigger uses Differential Difference Current Conveyor Transconductance Amplifier (DDCCTA)}

A Schmitt trigger circuit [11] is devised by availing the active device, namely, Differential Difference Current Conveyor Transconductnace Amplifier (DDCCTA) and is shown in Figure 5. For the devised circuit, the triggering points are given as,

$$
I_{O}=\left\{\begin{array}{l}
-I_{B} \text { for }_{i}>0 \\
+I_{B} \text { for } I_{i}<0
\end{array}\right\}
$$

The devised circuit is simulated in Cadence Virtuoso by using a 180nm CMOS process and operates with $\pm 2 \mathrm{~V}$ supply voltage. The advantage of this circuit is the output amplitudes can be adjustable with the help of bias currents which in turn changes the transconductance value. The disadvantage of this circuit is usage of $\pm 2 \mathrm{~V}$ supply voltage along with the power dissipation is more.

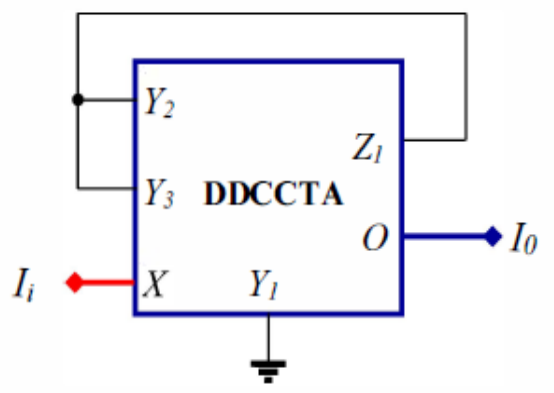

Figure. 5 Schmitt trigger using DDCCTA

F. Schmitt trigger uses Z-Copy Current Differencing Transconductance Amplifier (ZCCDTA)

Figure 6 shows a ZC-CDTA based Schmitt trigger circuit [13]. The circuit shown in Figure 6 has only one ZC- CDTA along with current directions of all port terminals. The output current of Schmitt trigger is given as

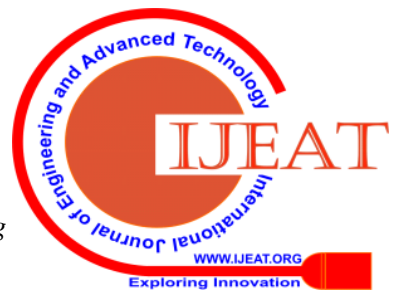




$$
\frac{I_{\text {out }}}{I_{\text {in }}}=\frac{R_{1}}{\left(R_{1}+R_{2}\right)}
$$

The designed Schmitt trigger circuit is simulated in Cadence Virtuoso tool with the use of gpdk $180 \mathrm{~nm}$ technology.

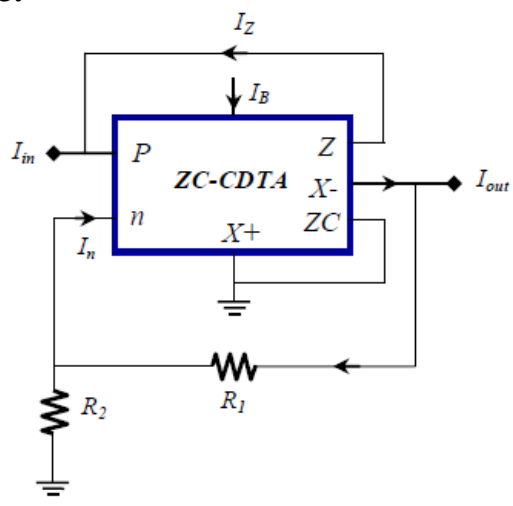

Figure. 6 ZC-CDTA based Schmitt trigger

The advantage of this circuit is operated at low voltage i.e., $\pm 0.85 \mathrm{~V}$. The disadvantage of the circuit is usage of two resistors; the circuit is complex in nature.

\section{G. Schmitt trigger uses Voltage Difference Transconductance Amplifier (VDTA)}

A Schmitt trigger circuit [14] using the VDTA active device is shown in Figure 7. The circuit is implemented by using one VDTA block along with single resistor.

The output voltage of Schmitt trigger is given as

$$
V_{O}=\left\{\begin{array}{r}
-I_{B 2} R \text { when } V_{\text {in }} \geq V_{P} \\
I_{B 2} R \text { when } V_{\text {in }} \leq V_{P}
\end{array}\right\}
$$

Figure. 7 VDTA based Schmitt trigger

The upper triggering point and the lower triggering point are given as,

$$
\begin{gathered}
V_{T H}=\frac{2 V_{T}}{I_{B 1}} I_{Z}+I_{B 2} R \\
V_{T L}=\frac{2 V_{T}}{I_{B 1}} I_{Z}-I_{B 2} R
\end{gathered}
$$

The advantage of this circuit is the output amplitudes can be adjustable with the help of bias currents which in turn changes the transconductance value. The disadvantage of the circuit is usage of single resistor and avails $\pm 1.5 \mathrm{~V}$ along with the power dissipation is more.

\section{RESULT DESCRIPTION}

In this paper, a numerous Schmitt trigger circuits are provided and are implemented with different active devices. The internal circuit of active devices is structured by using transistor technology. The primary criteria is, the designed Schmitt circuit must use less number of passive elements either resistor or capacitor along with the use of minimum active devices. The circuits which are implemented without the use of resistor provide a major advantage is that, the fabrication is easy in VLSI design. Table I provides the state-of-theart Schmitt triggers in the literature.

TABLE I: Comparitive Analysis Of Candidate Designs

\begin{tabular}{|c|c|c|c|}
\hline Ref & $\begin{array}{c}\text { Type of } \\
\text { Active } \\
\text { Element }\end{array}$ & $\begin{array}{c}\text { No. of } \\
\text { Active } \\
\text { Blocks }\end{array}$ & $\begin{array}{c}\text { No. of } \\
\text { Passive } \\
\text { Elements }\end{array}$ \\
\hline$[2]$ & Op-Amp & 1 & 3 \\
\hline$[3]$ & OTA & 2 & 2 \\
\hline$[4]$ & CCII+ & 1 & 3 \\
\hline$[10]$ & DDCC & 1 & 2 \\
\hline$[11]$ & DDCCTA & 1 & 0 \\
\hline$[13]$ & ZC-CDTA & 1 & 2 \\
\hline$[14]$ & VDTA & 1 & 1 \\
\hline
\end{tabular}

\section{CONCLUSION}

This paper represents an overview of designed Schmitt trigger circuits with the use of various active devices along with resistors. Some of the Schmitt trigger circuits are designed without using passive elements i.e., resistor. This makes an advantageous feature for easy implementation and manufacturing of integrated circuits in VLSI design. Schmitt trigger circuits are used in various applications such as, in analog signal processing, communication systems, wave-shaping circuits, Biomedical instrumentation, Waveform generators and so on.

\section{REFERENCES}

1. O. H. Schmitt, "A thermionic trigger", Journal of Scientific Instruments, vol. 15, no. 1, 1938.

2. A. S. Sedra and K. C. Smith, "Microelectronics Circuits", 4th Ed. Oxford University Press, pp. 1002-1005, 1998.

3. K.Kim, H. W. Cha and W. S. Chung, "OTA-R Schmitt trigger with independently controllable threshold and output voltage levels", Electronic Letters, vol. 33, no. 13, pp. 1103-1105, 1997, DOI: 10.1049/el:19970786.

4. G. Di Catadlo, G. Palumbo, S. Pennisi, "A Schmitt trigger by means of a CCII+", International Journal of Circuit Theory and Applications, vol. 23, no. 2, pp. 161-165, 1995, DOI: 10.1002/cta.4490230207.

5. D. Pal, A. Srinivasulu and M. Goswami, "Novel current-mode waveform generator with independent frequency and amplitude control", in Proc. of the IEEE International Symposium on Circuits and Systems, pp. 2946-2949, 2009, DOI: 10.1109/ISCAS. 2009.5118420.

6. AvireniSrinivasulu, "Current conveyor based relaxation oscillator with tunable grounded resistor/capacitor", International Journal of Design, Analysis and Tools for Circuits and Systems (Hong-Kong), vol. 3, no. 2, pp. 1-7, 2012.

7. S. Minaei and E. Yuce, "A Simple Schmitt Trigger Circuit with Grounded Passive Elements and Its Application to Square/Triangular Generator", Circuits, Systems and Signal Processing, vol. 31, pp. 877-888, 2012, DOI 10.1007/s00034011-9373-y.

8. H. Kim, H. J. Kim and W. S. Chung, "Pulse width modulation circuits using CMOS OTAs", IEEE Transactions on Circuits and Systems-I, vol. 54, no. 9, pp. 1869-1878, 2007. 
9. D. Pal, A. Srinivasulu, B. B. Pal, A. Demosthenous and B. N. Das, "current conveyor-based Square/Triangular wave generators with improved linearity", IEEE Trans. Instrumentation and Measurement, vol. 58, no. 7, pp. 2174-2180, 2009, DOI: 10.1109/TIM.2008.2006729.

10. Rupam Das, Khushi Banerjee, Ashmi Chakraborty, Lipika Mondal "Differential Difference Current Conveyor (DDCC) based Schmitt trigger circuit \& its Application", International Journal on Recent and Innovation Trends in Computing and Communication, Vol. 4, Issue. 8, pp. 69-72, 2016.

11. R. Linitha, A. Srinivasulu and V. Venkata Reddy, "A Schmitt Trigger Based on DDCCTA without any Passive Components", IEEE International Conference on Communications and Signal Processing, pp. 1695-1698, 2015, DOI: 10.1109/ICCSP.2015.7322808.

12. P. Sillapan and M. Siripruchyanum, "Fully and electronically controllable current-mode Schmitt triggers employing only single MO-CCCDTA and their applications", Analog Integrated Circuits Signals and Processing, vol. 68, issue. 1, pp. 111-128, 2011, https://doi.org/10.1007/s10470-010-9593-2.

13. Suma Madira, V.Venkata Reddy and AvireniSrinivasulu, "Current Mode Schmitt Trigger Based On ZC-Current Differencing Transconductance Amplifier", International Conference on Inventive Computation Technologies (ICICT), vol. 1, pp. 1-5, 2016, DOI: 10.1109/INVENTIVE.2016.7823226.

14. M. Siripruchyanun, P. Satthaphol and K. Payakkakul, "A Simple Fully Controllable Schmitt Trigger with Electronic method using VDTA", Applied Mechanics and Materials, Trans Tech Publications, vol. 781, pp. 180-183, 2015, DOI: 10.4028/www.scientific.net/AMM.781.180. 